\title{
Executive control in bilinguals: a concise review on $\mathrm{fMRI}$ studies
}

Article

Accepted Version

Pliatsikas, C. and Luk, G. (2016) Executive control in bilinguals: a concise review on fMRI studies. Bilingualism: Language and Cognition, 19 (4). pp. 699-705. ISSN 14691841 doi: https://doi.org/10.1017/S1366728916000249 Available at https://centaur.reading.ac.uk/54554/

It is advisable to refer to the publisher's version if you intend to cite from the work. See Guidance on citing.

To link to this article DOI: http://dx.doi.org/10.1017/S1366728916000249

Publisher: Cambridge University Press

All outputs in CentAUR are protected by Intellectual Property Rights law, including copyright law. Copyright and IPR is retained by the creators or other copyright holders. Terms and conditions for use of this material are defined in the End User Agreement.

\section{www.reading.ac.uk/centaur}

\section{CentAUR}

Central Archive at the University of Reading

Reading's research outputs online 


\title{
AUTHOR'S ACCEPTED VERSION
}

RUNNING HEAD: Executive control in bilinguals

Executive control in bilinguals: A concise review on fMRI studies

\author{
Christos Pliatsikas \\ Department of Clinical Language Sciences \\ School of Psychology and Clinical Language Sciences \\ University of Reading
}

\section{Gigi Luk}

Harvard Graduate School of Education

Address for correspondence:

Christos Pliatsikas, Ph. D.

University of Reading

Department of Clinical Language Sciences

School of Psychology and Clinical Language Sciences

Reading, RG6 6AL, UK

c.pliatsikas@reading.ac.uk 
Abstract

The investigation of bilingualism and cognition has been enriched by recent developments in functional magnetic resonance imaging (fMRI). Extending how bilingual experience shapes cognition, this review examines recent fMRI studies adopting executive control tasks with minimal or no linguistic demands. Across a range of studies with divergent ages and language pairs spoken by bilinguals, brain regions supporting executive control significantly overlap with brain regions recruited for language control (Abutalebi \& Green, this issue). Furthermore, limited but emerging studies on resting-state networks are addressed, which suggest more coherent spatially distributed functional connectivity in bilinguals. Given the dynamic nature of bilingual experience, it is essential to consider both task-related functional networks (externallydriven engagement), and resting-state networks, such as default mode network (internal control). Both types of networks are important elements of bilingual language control, which relies on domain-general executive control.

executive control, functional magnetic resonance imaging (fMRI), bilingual experience, restingstate

\section{Introduction}

Bilinguals' ability to control and manage two or more languages has been the centre of investigation for researchers in psychology, linguistics, and more recently cognitive neuroscience. Of particular interest is how bilinguals and monolinguals, contrasting in their language experiences, engage neural resources to complete tasks that require linguistic processing, such as phonetic perception (Golestani, this issue), reading (Cao, this issue), and morphosyntactic processing (Roncaglia-Denissen \& Kotz, 2015). Recently, there is an increasing 
amount of research comparing functional activity in monolinguals and bilinguals using executive control tasks. The examination of functional brain regions supporting domain-general executive control in bilinguals furthers current investigation of how language experience shapes cognition (Costa \& Sebastián-Gallés, 2014), an aspect of how experience-expectant and experiencedependent mechanisms interact in human development (Greenough, Black \& Wallace, 1987).

Theoretical accounts connecting bilingual experience to domain-general cognition were initiated by Green's (1998) Inhibitory Control (IC) model, which was proposed as an expansion to Kroll and Stewart's (1994) Revised Hierarchical model. Empirical evidence from behavioural research (e.g., Blumenfeld \& Marian, 2014) and, more recently, neuroimaging research, has shown support for Green's original IC model (e.g., see a recent study by Coderre, Smith, van Heuven \& Horwitz, 2015). The IC model was later extended to incorporate brain regions associated with control of multiple languages (Abutalebi \& Green, 2008) and the interactional context (Green \& Abutalebi, 2013). To elucidate how bilinguals deploy neural resources adapting to domain-general executive control, we review functional magnetic resonance imaging (fMRI) studies that report functional activation in monolinguals and bilinguals while completing executive control tasks that demand little linguistic processing. Furthermore, recent studies examining resting-state functional connectivity are also included. The review ends with theoretical and methodological considerations in advancing the investigation of bilingualism and cognition through the neuroimaging lens.

\section{Common and distinct brain regions supporting executive control in monolinguals and bilinguals}


The examination of bilingualism and cognition has focused on executive control, a set of skills sustaining goal-directed behaviour (for reviews, see Bialystok, Craik \& Luk, 2012; Valian, 2015). The same tasks are gradually being used with fMRI designs, in order to investigate the neural correlates of executive control in bilinguals. One of these tasks is the Simon task (Bialystok, Craik, Klein \& Viswanathan, 2004): in its simplest form, the Simon task involves responding to the colour of a given shape on the screen by pressing a pre-assigned button, e.g., a button on the left side of the keyboard for red and a button on the right side of the keyboard for blue. However, the placement of the shape on the screen can vary between two positions: either corresponding to the assigned arbitrary side, e.g., a red shape placed on the left of the screen (Congruent trials) or appearing on the opposite side of the screen, e.g., a red shape on the right of the screen (Incongruent trials).

One recent fMRI study adopting the Simon paradigm was reported by Mohades, Struys, Van Schuerbeek, Baeken, Van De Craen and Luypaert (2014), who compared activation in an event-related design across three groups of children: simultaneous bilinguals, successive early bilinguals, and monolinguals. Mohades et al. found significantly higher activity in incongruent trials relative to congruent trials (in response to the increased demand in ignoring the position of stimulus) in both bilingual groups compared to monolinguals in the following brain areas: left superior temporal gyrus, bilateral posterior cingulate gyrus, right middle frontal gyrus, and right caudate nucleus. A small difference between the two bilingual groups was observed in the Right Inferior Frontal Gyrus (RIFG) but did not reach statistical significance. The authors speculated that the activation of the caudate nucleus as an area RESOLVING CONFLICT arises from processing verbal and non-verbal stimuli (Bialystok, Craik, Green \& Gollan, 2009), and the activation in the posterior cingulate gyrus is associated with the role of WORKING MEMORY in the particular task. 
However, a recent study with an aging sample showed increased activation in the left inferior parietal lobule in bilinguals, but increased activation of the right middle frontal gyrus for monolinguals for incongruent versus control trials. (Ansaldo, Ghazi-Saidi \& Adrover-Roig, 2015). The authors suggested that this pattern might be due to the fact that older long-term bilinguals have developed more efficient executive controlling than children, meaning that they do not need to activate the network described in Mohades et al. (2014) in order to resolve conflicts. For the same reason, parts of this network were activated for only the monolinguals, who did not have a life-long experience of linguistic conflict monitoring.

Another classic behavioural task that taps into executive function is the Stroop task (MacLeod, 1992). Participants are typically asked to name the colour of the ink that a presented colour word is printed in (the word 'red' printed in red or blue ink) and refraining from reading the word. Similarly, a congruency effect can be extracted by comparing performance in congruent trials (when the word 'red' is printed in red) relative to incongruent trials (when the word 'red' is printed in blue). Like a Simon task, each stimulus embeds information relevant to decision-making (colour of printed word in Stroop, rules attached to response in Simon) and distracting from correct decision-making (literal meaning of words in Stroop, position of stimulus in Simon). Neuroimaging results from the Stroop task were more straightforward: Mohades et al. (2014) found that that both bilingual groups showed increased activation in the anterior cingulate gyrus, a region that has been linked to error detection and monitoring of conflicts (Botvinick, Cohen \& Carter, 2004).

In addition to Simon and Stroop paradigms, the Flanker paradigm has also been adopted extensively in the behavioural literature. In its simplest form, the participant sees five arrows on a screen, and has to respond to the direction of the central arrow by pressing the appropriate 
button (i.e., right or left). On the Congruent trials, the middle arrow is flanked by arrows pointing in the same direction, whilst on the Incongruent trials the flanking arrows point to the opposite direction. Similar to the Simon and Stroop tasks, congruency effect is again observed by comparing the costs in response time and/or accuracy in incongruent trials relative to congruent trials. To date, two studies have incorporated the Flanker task into an fMRI design investigating the effects of bilingualism on executive control.

Luk, Anderson, Craik, Grady and Bialystok (2010) tested young bilinguals and monolinguals on an adapted Flanker task in which a NoGo trial type was included in addition to congruent and incongruent trials. The NoGo trials consisted of an arrow flanked by the letter ' $\mathrm{X}$ ', to which participants were instructed to refrain from responding. The NoGo trials allowed Luk et al. to differentiate between suppressing an interfering response in incongruent trials (as in the standard Flanker or Simon tasks) and inhibiting a behavioural response altogether. When comparing the brain activity for Congruent, Incongruent and NoGo trials, Luk and colleagues reported that a common distributed network was activated in bilinguals for both the Incongruent (interference suppression) and the NoGo trials (response inhibition). This network included the bilateral inferior frontal and temporal cortices, as well as subcortical regions, which have all been implicated in cognitive control (Aron, Behrens, Smith, Frank \& Poldrack, 2007). Conversely, the same network was used by monolinguals for the NoGo trials only, whereas the incongruent trials were processed by a smaller network, including left temporal pole and left superior parietal lobule. Luk and colleagues provided two interpretations for their findings: (a) response inhibition and response selection are distinguishable but related processes; and (b) the recruitment of the more distributed network for response selection by bilinguals suggests that they can rely on this network for interference suppression more successfully than monolinguals. Luk and colleagues 
suggested that this extensive usage of brain areas in bilinguals in response to interference suppression is related to bilinguals' constant need to suppress the interference from one language at any given time.

Another type of tasks that has been commonly used in the relevant literature is the colour-shape switching tasks. Several versions of this task have been adopted to use in fMRI designs. For example, Garbin, Sanjuan, Forn, Bustamante, Rodríguez-Pujadas, Belloch, Hernandez, Costa, and Ávila (2010) compared young early bilinguals and monolinguals on responding to the colour or the shape of figures presented on the screen, based on a cue word (e.g., 'colour' or 'shape') and by pressing pre-assigned buttons. The 'colour' and 'shape' cues are presented randomly, creating Switch trials, i.e., 'colour' preceded by 'shape' and vice versa, and Non-switch trials, i.e., consecutively presented 'colour' or 'shape' trials. The predictions for this task would be that the switch trials would activate areas known to underlie language switching in bilinguals, such as the left inferior frontal gyrus (LIFG), anterior cingulate cortex (ACC), left inferior parietal lobe and left basal ganglia (Green \& Abutalebi, 2013).

Garbin and colleagues reported increased activation in LIFG for bilinguals when responding to Switch trials, relative to Non-switch trials, whereas monolinguals showed increased activation in the RIFG and insula, ACC and left inferior parietal lobe (although most of these effects did not survive the between-groups statistical comparison). These areas are consistent with brain regions supporting bilingual language control (Abutalebi \& Green, this issue; Green \& Abutalebi, 2013). Importantly, the authors considered increased activation in LIFG as an indication of bilinguals' greater ability to control inappropriate responses in conflict tasks, reaching a similar conclusion as that in Luk, Green, Abutalebi and Grady (2011) (see also Coderre et al., 2015, for similar conclusions from the Flanker paradigm). This was further 
supported by a negative correlation between the activation of this region and the switching cost as extracted from the behavioural data of this study. Similar results were presented by Rodríguez-Pujadas, Sanjuán, Ventura-Campos, Román, Martin, Barceló, Costa and Ávila (2013). In this study, the authors reported that bilinguals showed increased activity in the caudate nucleus when responding to Switch trials. Finally, Gold, Kim, Johnson, Kryscio and Smith (2013) compared young and elderly bilinguals and monolinguals in a similar task-switching paradigm. Gold et al. reported that brain activity in response to Switch trials compared to Nonswitch trials (or THE SWITCHING COST) was observed in the following brain regions across all groups: bilateral dorsolateral prefrontal cortex (DLPFC), ventrolateral prefrontal cortex (VLPFC), supramarginal gyrus (SMG) and ACC. Interestingly, older bilinguals demonstrated significantly lower switching costs than monolinguals in left DLPFC and VLPFC and ACC, and this pattern of effects did not significantly differ from that for young bilinguals and monolinguals. No other significant differences were found within these areas, including no differences between young bilinguals and monolinguals. Gold et al. suggested that their findings constitute evidence for the neuroprotective effects of bilingualism; most importantly, the areas demonstrating the reduced switching costs (ACC and left DLPFC and VLPFC) overlap with the areas suggested to underlie language switching (Green \& Abutalebi, 2013), meaning that lifelong switching between languages might bring about benefits that extend to domain-general executive control.

Earlier neuroimaging studies focus almost exclusively on how bilinguals switch between languages, or suppress their L1 while speaking in L2 or vice versa, and the brain correlates of switching and/or suppressing languages. An extensive review of this literature is beyond the scope of this review, as we wish to focus on the effects of bilingualism on executive control. A 
detailed review can be found in Green and Abutalebi (2013) and Abutalebi and Green (Abutalebi \& Green), while some more recent evidence has been provided by Branzi, Della Rosa, Canini, Costa and Abutalebi (2015), De Baene, Duyck, Brass and Carreiras, (2015), de Bruin, Roelofs, Dijkstra and FitzPatrick (2014), Grant, Fang and Li (2015), Lei, Akama and Murphy (2014), Reverberi, Kuhlen, Abutalebi, Greulich, Costa, Seyed-Allaei, and Haynes (2015), and Wattendorf, Festman, Westermann, Keil, Zappatore, Franceschini, Luedi, Radue, Münte and Nitsch (2014). To find direct evidence of overlapping brain regions responding to executive control tasks using linguistic and non-linguistic stimuli, Coderre and colleagues (2015) adapted the Flanker paradigm to utilize words in L1 or L2 as flankers. Data were collapsed over congruency and were compared to the control condition (i.e., when the target arrow was not flanked by either congruent or incongruent arrows). In this case, no flanker effects or betweengroup differences were reported (although it is worth noting that some of the monolinguals did report having acquired an additional language). In a conjunction analysis, the authors reported only bilinguals showing activation in left inferior frontal gyrus and left posterior cingulate cortex when considering both linguistic and non-linguistic processing relative to control (a semantic categorization). No significant conjunction cluster was observed in monolinguals. Since these regions have been shown to be related to attentional control (Bunge, Dudukovic, Thomason, Vaidya, \& Gabrieli, 2002; Milham, Banich \& Barad, 2003), Coderre and colleagues suggested that the functional overlap reflects the interdependence between language use and domaingeneral executive control. Notably, Weissberger, Gollan, Bondi, Clark and Wierenga (2015) directly compared linguistic and non-linguistic switching in bilinguals and reported significant overlaps between the brain areas recruited in the switching trials for both tasks, including large bilateral cortical and subcortical regions, with the language task only activating the thalamus, 
right caudate and cingulate gyrus more than the non-linguistic task. Taken together, empirical evidence aiming to identify overlapping brain regions between language and executive control is consistent with brain regions proposed by Abutalebi and Green's adaptive control hypothesis (this issue).

\section{Resting-state networks}

Although the literature on the effects of bilingualism on brain function over executive control tasks is growing considerably, the literature of the effects of bilingualism on the resting brain remains remarkably limited, despite the fact that recent evident suggests that resting-state connectivity can be a predictor of second language acquisition (Chai, Berken, Barbeau, Soles, Callahan, Chen, \& Klein, 2016). The first study to investigate the effects of bilingualism on resting state functional connectivity was by Luk, Bialystok, Craik and Grady (2011). After having identified fractional anisotropy differences between older lifelong bilinguals and monolinguals in the corpus callosum, Luk and colleagues focused on the functional correlates of this structural difference. Specifically, Luk and colleagues hypothesized that greater difference in fractional anisotropy in white matter would express itself as a more distributed functional network. To investigate this possibility, Luk and colleagues performed a seed-based analysis on resting-state functional data, using as seed a voxel in RIFG near an area with significant difference in fractional anisotropy, as well as its homologue in the LIFG, consistent with a previous meta-analysis (Luk et al., 2011) and previous research. For both seeds, bilinguals demonstrated increased functional connectivity with bilateral temporal, parietal and occipital areas, and the left caudate, whereas monolinguals showed increased connectivity with other frontal areas. Luk and colleagues considered these effects as evidence for a more distributed 
functional connectivity, which they linked to the documented structural connectivity, and they interpreted both effects as evidence for the 'cognitive reserve' associated with bilingual experience (Bialystok et al., 2012).

To further the investigation in whether bilingual experience alters resting-state brain networks, Grady, Luk, Craik and Bialystok (2015) compared resting state connectivity between older bilinguals and monolinguals by focusing on three resting state networks that are known to be related to executive control. These were the frontoparietal control network (FPC), including dorsolateral and inferior frontal regions and inferior parietal regions (Spreng, Sepulcre, Turner, Stevens \& Schacter, 2013), the salience network (SLN), including the anterior insula, the dorsal anterior cingulate gyrus and the supramarginal gyri (Seeley, Menon, Schatzberg, Keller, Glover, Kenna, Reiss \& Greicius, 2007), and the default mode network (DMN), including the posterior cingulate gyrus, the ventromedial prefrontal cortex, the angular gyri and the parahippocampal gyri (Spreng, Mar \& Kim, 2009). Grady and colleagues reported greater functional connectivity in bilinguals for both the DMN and FPC networks, but not for the SLN network. Interestingly, these effects are similar to the anterior-parietal effects reported in Luk et al. (2011), further supporting the hypothesis that any differences in functional connectivity between bilinguals and monolinguals are located in networks underlying higher cognitive control, but not in areas responsible for primary processing of sensory information (for similar results, and also the effects of L2 age of acquisition on resting state connectivity, see Berken, Chai, Chen, Gracco, \& Klein, 2016). Grady and colleagues also explained the absence of effects in the SLN to the fact that this network includes limbic structures which are involved in emotional processing, and therefore may be less sensitive to the effects of diverse language experience. 
Further insights into resting state connectivity in bilinguals were provided by $\mathrm{Li}$, Abutalebi, Zou, Yan, Liu, Feng, Wang, Guo and Ding (2015), who compared middle-aged Chinese bimodal bilinguals to monolinguals. Li and colleagues focused on the connectivity between two sets of regions-of-interests (ROIs): first, two ROIs that are known to be involved in language control, namely dorsal anterior cingulate cortex (dACC) (Abutalebi, Della Rosa, Green, Hernandez, Scifo, Keim, Cappa, \& Costa, 2012) and left caudate nucleus (LCN) (Zou, Ding, Abutalebi, Shu \& Peng, 2012). Second, ten ROIs involved in language processing (from Zou et al., 2012), classified as follows: (a) ROIs activated for both sign and spoken language processing, e.g., the bilateral precentral gyrus (PCG). (b) ROIs specific to spoken language processing, e.g., the bilateral superior temporal gyrus (STG), and (c) ROIs specific to sign language processing, e.g., the bilateral posterior middle temporal gyrus (MTG). Li et al. found decreased functional connectivity between the $\mathrm{dACC}$ and spoken language-specific ROIs, more specifically the left STG and rolandic operculum. The authors attributed this effect to 'less developed function' of these ROIs, which is in turn related to the bilinguals using spoken language less frequently than monolingual speakers in everyday life. No other significant effects were found. Results support that bimodal bilingualism specifically alters functional connectivity between brain regions sensitive to modality of language representations, but not those responsible for language control. This last finding does not necessarily contrast with previous claims; it is possible that dealing with two languages in different domains (spoken and language) requires quantitatively and qualitatively different executive control than unimodal bilingualism.

\section{Conclusions}


In this review, similar and differential brain regions were observed in bilinguals when engaging in executive control tasks compared to monolinguals. Critically, these brain regions converge on those hypothesized to be involved in bilingual language control (Abutalebi \& Green, 2008 and in this issue; Green \& Abutalebi, 2013). Current neuroimaging research on bilingualism and executive control has emerged into an exciting stage. Two emerging trends warrant further investigation: (1) beyond task-related functional networks; and (2) behavioural correlates with functional differences observed in bilinguals compared to monolinguals. We comment on each trend in turn.

Research attention has demonstrated a transition from adopting traditional behavioural executive control tasks to examining the functional connectivity of task-related and resting-state networks, specifically the default mode network. We argue that both task-related and restingstate networks are essential to understanding the bilingual mind and brain. As bilinguals constantly manage multiple languages, by focusing on the target language in use and ignoring interference from the unwanted languages, a cascade of decision-making is involved: interaction in the environment forms EXOGENOUS factors biasing ENDOGENOUS decision as to which language to attend to (and which to disregard). The need to balance exogenous factors with endogenous decision-making can be considered in task-related and resting-state networks in which individuals are driven to direct attention to the external environment and internal domain, both of which are modulated by underlying goal-directed objective (Spreng, DuPre, Selarka, Garcia, Gojkovic, Mildner, Luh \& Turner, 2014).

Related to the possible trend of examining network dynamics related to language experience and executive control, another trend is to consider what pattern of brain activation is considered as showing efficient or optimal behavioural performance. Across current studies, 
increased brain activation associated with conditions of interest, such as incongruent or switch trials, reflects that certain brain regions are recruited to support the cognitive processing of interest (e.g., Mohades et al., 2014). This neural correlate has been speculated as the source of advanced behaviour relating to executive control. Arguably, decreased brain activity may reflect more efficient recruitment of brain functions (e.g., Ansaldo et al., 2015). In either case, it is insufficient to claim a behavioural difference in light of separate investigation of brain activity and behaviour. However, few studies substantiated this reflection by synthesizing multi-modal data (brain function, behaviour, and brain structure). In order to elucidate and advance current understanding on how diverse language experience enriches cognition through shaping our brains, it is essential to consider the brain-behaviour relationship.

In conclusion, bilingual experience has consequences beyond language processing. Neuroimaging tools enable the study of bilingualism to be a transdisciplinary field. Building on existing research, innovative methods on functional and structural networks along with comprehensive investigation of brain function and behaviour is beneficial to understanding the neural mechanism supporting executive control in individuals with diverse language experiences. 


\section{References}

Abutalebi, J., \& Green, D. (this issue). Neuroimaging of language control in bilinguals: Neural adaptation and reserve. Bilingualism: Language and cognition

Abutalebi, J., \& Green, D. (2008). Control mechanisms in bilingual language production: neural evidence from language switching studies. Language and Cognitive Processes, 23(4), 557582. http://doi.org/10.1080/01690960801920602

Abutalebi, J., Della Rosa, P. A., Green, D. W., Hernandez, M., Scifo, P., Keim, R., Cappa, S., \& Costa, A. (2012). Bilingualism tunes the anterior cingulate cortex for conflict monitoring. Cerebral Cortex, 22(9), 2076-2086. http://doi.org/10.1093/cercor/bhr287

Ansaldo, A. I., Ghazi-Saidi, L., \& Adrover-Roig, D. (2015). Interference control in elderly bilinguals: Appearances can be misleading. Journal of Clinical and Experimental Neuropsychology, 37(5), 455-470. http://doi.org/10.1080/13803395.2014.990359

Aron, A. R., Behrens, T. E., Smith, S., Frank, M. J., \& Poldrack, R. A. (2007). Triangulating a cognitive control network using diffusion-weighted magnetic resonance imaging (MRI) and Functional MRI. Journal of Neuroscience, 27(14), 3743-3752. http://doi.org/10.1523/JNEUROSCI.0519-07.2007

Berken, J. A., Chai, X., Chen, J.-K., Gracco, V. L., \& Klein, D. (2016). Effects of Early and Late Bilingualism on Resting-State Functional Connectivity. Journal of Neuroscience, 36(4), 1165-1172. http://doi.org/10.1523/JNEUROSCI.1960-15.2016

Bialystok, E., Craik, F., Green, D., \& Gollan, T. (2009). Bilingual minds. Psychological Science in the Public Interest, 10(3), 89-129. http://doi.org/10.1177/1529100610387084

Bialystok, E., Craik, F. I. M., Klein, R., \& Viswanathan, M. (2004). Bilingualism, aging, and cognitive control: Evidence from the Simon task. Psychology and Aging, 19(2), 290-303. 
http://doi.org/10.1037/0882-7974.19.2.290

Bialystok, E., Craik, F. I. M., \& Luk, G. (2012). Bilingualism: consequences for mind and brain. Trends in Cognitive Sciences, 16(4), 240-50. http://doi.org/10.1016/j.tics.2012.03.001

Blumenfeld, H. K., \& Marian, V. (2014). Cognitive control in bilinguals: Advantages in Stimulus-Stimulus inhibition. Bilingualism: Language and Cognition,17(3), 610-629. http://doi.org/10.1017/S1366728913000564

Botvinick, M. M., Cohen, J. D., \& Carter, C. S. (2004). Conflict monitoring and anterior cingulate cortex: an update. Trends in Cognitive Sciences, 8(12), 539-546. http://doi.org/10.1016/j.tics.2004.10.003

Branzi, F. M., Rosa, P. A. Della, Canini, M., Costa, A., \& Abutalebi, J. (2015). Language control in bilinguals: monitoring and response selection. Cerebral Cortex. Advance Access, 1-14 http://doi.org/10.1093/cercor/bhv052

Bunge, S. A., Dudukovic, N. M., Thomason, M. E., Vaidya, C. J., \& Gabrieli, J. D. E. (2002). Immature frontal lobe contributions to cognitive control in children. Neuron, 33(2), 301311. http://doi.org/10.1016/S0896-6273(01)00583-9

Cao, F. (2015). Neuroimaging studies of reading in bilinguals. Bilingualism: Language and Cognition. DOI: http://dx.doi.org/10.1017/S1366728915000656

Chai, X. J., Berken, J. A., Barbeau, E. B., Soles, J., Callahan, M., Chen, J.-K., \& Klein, D. (2016). Intrinsic Functional Connectivity in the Adult Brain and Success in SecondLanguage Learning. Journal of Neuroscience, 36(3), 755-761. http://doi.org/10.1523/JNEUROSCI.2234-15.2016 
Coderre, E. L., Smith, J. F., van Heuven, W. J. B., \& Horwitz, B. (2015). The functional overlap of executive control and language processing in bilinguals. Bilingualism: Language and Cognition, 1-18. http://doi.org/10.1017/S1366728915000188

Costa, A., \& Sebastián-Gallés, N. (2014). How does the bilingual experience sculpt the brain? Nature Reviews Neuroscience, 15(5), 336-345. http://doi.org/10.1038/nrn3709

De Baene, W., Duyck, W., Brass, M., \& Carreiras, M. (2015). Brain circuit for cognitive control is shared by task and language switching. Journal of Cognitive Neuroscience, 27(9), 17521765. http://doi.org/10.1162/jocn_a_00817

de Bruin, A., Roelofs, A., Dijkstra, T., \& FitzPatrick, I. (2014). Domain-general inhibition areas of the brain are involved in language switching: FMRI evidence from trilingual speakers. NeuroImage, 90, 348-359. http://doi.org/10.1016/j.neuroimage.2013.12.049

Garbin, G., Sanjuan, A., Forn, C., Bustamante, J. C., Rodríguez-Pujadas, A., Belloch, V., Hernandez, M., Costa., A., \& Ávila, C. (2010). Bridging language and attention: Brain basis of the impact of bilingualism on cognitive control. NeuroImage, 53(4), 1272-1278. http://doi.org/10.1016/j.neuroimage.2010.05.078

Gold, B. T., Kim, C., Johnson, N. F., Kryscio, R. J., \& Smith, C. D. (2013). Lifelong bilingualism maintains neural efficiency for cognitive control in aging. Journal of Neuroscience, 33(2), 387-396. http://doi.org/10.1523/JNEUROSCI.3837-12.2013

Golestani, N. (2015). Neuroimaging of phonetic perception in bilinguals. Bilingualism: Language and Cognition. DOI: http://dx.doi.org/10.1017/S1366728915000644

Grady, C. L., Luk, G., Craik, F. I. M., \& Bialystok, E. (2015). Brain network activity in monolingual and bilingual older adults. Neuropsychologia, 66, 170-181. http://doi.org/10.1016/j.neuropsychologia.2014.10.042 
Grant, A. M., Fang, S.-Y., \& Li, P. (2015). Second language lexical development and cognitive control: A longitudinal fMRI study. Brain and Language, 144, 35-47. http://doi.org/10.1016/j.bandl.2015.03.010

Green, D. W. (1998). Mental control of the bilingual lexico-semantic system. Bilingualism: Language and Cognition, 1(02), 67-81. http://doi.org/10.1017/S1366728998000133

Green, D. W., \& Abutalebi, J. (2013). Language control in bilinguals: The adaptive control hypothesis. Journal of Cognitive Psychology, 25,1-16. http://doi.org/10.1080/20445911.2013.796377

Greenough, W. T., Black, J. E., \& Wallace, C. E. (1987). Experience and brain development. Child Development, 58(3), 539-559.

Kroll, J. F., \& Stewart, E. (1994). Category interference in translation and picture naming: Evidence for asymmetric connections between bilingual memory representations. Journal of Memory and Language, 33(2), 149-174. http://doi.org/10.1006/jmla.1994.1008

Lei, M., Akama, H., \& Murphy, B. (2014). Neural basis of language switching in the brain: fMRI evidence from Korean-Chinese early bilinguals. Brain and Language, 138c, 12-18. http://doi.org/10.1016/j.bandl.2014.08.009

Li, L., Abutalebi, J., Zou, L., Yan, X., Liu, L., Feng, X., Wang, R., Guo, T., \& Ding, G. (2015). Bilingualism alters brain functional connectivity between "control" regions and "language" regions: Evidence from bimodal bilinguals. Neuropsychologia, 71, 236-247 http://doi.org/10.1016/j.neuropsychologia.2015.04.007

Luk, G., Anderson, J. A. E., Craik, F. I. M., Grady, C., \& Bialystok, E. (2010). Distinct neural correlates for two types of inhibition in bilinguals: Response inhibition versus interference 
suppression. Brain and Cognition, 74(3), 347-357.

http://doi.org/10.1016/j.bandc.2010.09.004

Luk, G., Bialystok, E., Craik, F. I. M., \& Grady, C. L. (2011). Lifelong bilingualism maintains white matter integrity in older adults. The Journal of Neuroscience, 31(46), 16808-13. http://doi.org/10.1523/JNEUROSCI.4563-11.2011

Luk, G., Green, D. W., Abutalebi, J., \& Grady, C. (2011). Cognitive control for language switching in bilinguals: A quantitative meta-analysis of functional neuroimaging studies. Language and Cognitive Processes, 27(10), 1479-1488. http://doi.org/10.1080/01690965.2011.613209

MacLeod, C. M. (1992). The Stroop task: The "gold standard" of attentional measures. Journal of Experimental Psychology: General, 121(1), 12-14 http://doi.org/10.1037/00963445.121 .1 .12

Milham, M. P., Banich, M. T., \& Barad, V. (2003). Competition for priority in processing increases prefrontal cortex's involvement in top-down control: An event-related fMRI study of the Stroop task. Cognitive Brain Research, 17(2), 212-222. http://doi.org/10.1016/S0926-6410(03)00108-3

Mohades, S. G., Struys, E., Van Schuerbeek, P., Baeken, C., Van De Craen, P., \& Luypaert, R. (2014). Age of second language acquisition affects nonverbal conflict processing in children: an fMRI study. Brain and Behavior, 4(5), 626-642.

http://doi.org/10.1002/brb3.246

Reverberi, C., Kuhlen, A., Abutalebi, J., Greulich, R. S., Costa, A., Seyed-Allaei, S., \& Haynes, J.-D. (2015). Language control in bilinguals: Intention to speak vs. execution of speech. Brain and Language, 144, 1-9. http://doi.org/10.1016/j.bandl.2015.03.004 
Rodríguez-Pujadas, A., Sanjuán, A., Ventura-Campos, N., Román, P., Martin, C., Barceló, F., Costa, A., \& Ávila, C. (2013). Bilinguals use language-control brain areas more than monolinguals to perform non-linguistic switching tasks. PLOS ONE, 8(9), e73028. http://doi.org/10.1371/journal.pone.0073028

Roncaglia-Denissen, M. P., \& Kotz, S. A. (2015). What does neuroimaging tell us about morphosyntactic processing in the brain of second language learners. Bilingualism: Language and Cognition. DOI: http://dx.doi.org/10.1017/S1366728915000413

Seeley, W. W., Menon, V., Schatzberg, A. F., Keller, J., Glover, G. H., Kenna, H., Reiss, A., \& Greicius, M. D. (2007). Dissociable intrinsic connectivity networks for salience processing and executive control. The Journal of Neuroscience, 27(9), 2349-2356. http://doi.org/10.1523/JNEUROSCI.5587-06.2007

Spreng, R. N., DuPre, E., Selarka, D., Garcia, J., Gojkovic, S., Mildner, J., Luh, W., \& Turner, G. R. (2014). Goal-congruent default network activity facilitates cognitive control. The Journal of Neuroscience, 34(42), 14108-14114. http://doi.org/10.1523/JNEUROSCI.281514.2014

Spreng, R. N., Mar, R. A., \& Kim, A. S. N. (2009). The common neural basis of autobiographical memory, prospection, navigation, theory of mind, and the default mode: A quantitative meta-analysis. Journal of Cognitive Neuroscience, 21(3), 489-510. http://doi.org/10.1162/jocn.2008.21029

Spreng, R. N., Sepulcre, J., Turner, G. R., Stevens, W. D., \& Schacter, D. L. (2013). Intrinsic architecture underlying the relations among the default, dorsal attention, and frontoparietal control networks of the human brain. Journal of Cognitive Neuroscience, 25(1), 74-86. http://doi.org/10.1162/jocn_a_00281 
Wattendorf, E., Festman, J., Westermann, B., Keil, U., Zappatore, D., Franceschini, R., Luedi, G., Radue, E., Münte, T., \& Nitsch, C. (2014). Early bilingualism influences early and subsequently later acquired languages in cortical regions representing control functions. International Journal of Bilingualism, 18(1), 48-66. http://doi.org/10.1177/1367006912456590

Weissberger, G. H., Gollan, T. H., Bondi, M. W., Clark, L. R., \& Wierenga, C. E. (2015). Language and task switching in the bilingual brain: Bilinguals are staying, not switching, experts. Neuropsychologia, 66, 193-203. http://doi.org/10.1016/j.neuropsychologia.2014.10.037

Valian, V. (2015). Bilingualism and cognition. Bilingualism: Language and Cognition, 18(1), 324. http://doi.org/10.1017/S1366728914000522

Zou, L., Ding, G., Abutalebi, J., Shu, H., \& Peng, D. (2012). Structural plasticity of the left caudate in bimodal bilinguals. Cortex, 48(9), 1197-206.

http://doi.org/10.1016/j.cortex.2011.05.022 